\title{
RUBEM FONSECA E O SELO DO TERROR
}

\author{
Gabriel Domício Medeiros Moura Freitas \\ $\mathrm{UFPB} / \mathrm{CNPq}$
}

RESUMO: Em 1969, o conto "0 quarto selo (Fragmento)", de Rubem Fonseca, é publicado no livro de contos intitulado Lúcia McCartney. Esta narrativa surge um ano depois da publicação do Ato Institucional $n^{0} 5$ (Al-5), o qual representou a potencialização do autoritarismo estatal no Brasil. Neste sentido, a relação entre tal circunstância histórica e o referido texto literário é considerada em nossa análise. A propósito, consideramos a inspiração relativa ao Apocalipse bíblico para a composição da respectiva trama, bem como os possíveis significados simbólicos decorrentes ali configurados. Assim, 0 terror e a brutalidade esteticamente representados podem ser entendidos em dois sentidos: uma sutil denúncia contra as práticas autoritárias estatais então vigentes; além disto, estas representações surgem como uma profecia distópica. Por outro lado, os momentos de ruptura da causalidade presentes na produção literária também são discutidos. Logo, eles são analisados segundo as relações entre forma e conteúdo artisticamente configuradas.

PALAVRAS-CHAVE: Rubem Fonseca. Conto. Ditadura.

\section{RUBEM FONSECA AND THE SEAL OF TERROR}

ABSTRACT: In 1969, the tale "0 quarto selo (Fragmento)", by Brazilian writer Rubem Fonseca, is published in a book entitled Lúcia McCartney. That story appears one year after the Institutional Act Number 5 (Al-5) publication, which represented the increase of government authoritarianism in Brazil. So, the relation among this historical circumstance and that narrative is taken into consideration in our analysis. For instance, we consider the Apocalypse an inspiration in this literary composition and the possible symbolical meanings configured there. In this context, the terror and brutality aesthetically represented can be understood as a subtle denounce against state authoritarian practices then figured and a dystopia prophecy. Furthermore, the moments of causality ruptures in that plot are also discussed. In this sense, they are analyzed according to the relation among form and constituted literary content.

KEYWORDS: Rubem Fonseca. Tale. Dictatorship.

Gabriel Domício Medeiros Moura Freitas | gabrielmoura@msn.com|é mestre em Letras e pesquisador vinculado ao Grupo de Pesquisa em Estudos de Literatura e Sociedade Contemporânea da Universidade Federal da Paraíba. 


\title{
RUBEM FONSECA E O SELO DO TERROR
}

\author{
Gabriel Domício Medeiros Moura Freitas
}

\section{APRESENTAÇÃO}

Desde sua estreia literária (Os prisioneiros, 1963), as narrativas de Rubem Fonseca são caracterizadas por apresentar situações bastante explícitas tanto de violência quanto referentes à sexualidade humana. A primeira obra deste escritor publicada durante a ditadura civil-militar brasileira (1964-1985) foi o livro de contos A coleira do cão (1965). Curiosamente, a censura somente decidiu investir contra uma de suas obras em 1976, proibindo a circulação de Feliz ano novo, publicado no ano anterior. Os efeitos desta proibição são tão severos que eles somente serão revogados quatro anos após a redemocratização ocorrer no Brasil.

Assim, um conto como "O quarto selo (Fragmento)" não ter sofrido qualquer censura pelo poder autoritário de então desperta atenção. Esta narrativa, desenvolvida no contexto distópico de um futuro próximo, está relacionada com o momento histórico de exacerbação do autoritarismo brasileiro então vigente. Possivelmente, a natureza profética e prospectiva deste texto literário tenha sido um dos fatores que contribuíram no sentido de tal desatenção a ele dirigida.

Neste sentido, analisaremos quais os possíveis efeitos de sentido relacionados a determinados momentos de ruptura de causalidade na trama deste conto. Para este fim, verificaremos as possibilidades de articulação destes procedimentos estéticos com as representações literárias do contexto sóciopolítico então vigente.

\section{O SELO DO TERROR ESTÁ ABERTO}

"O quarto selo (Fragmento)" foi publicado no livro Lúcia McCartney ${ }^{1}$ em

\footnotetext{
1 FONSECA, Rubem. O quarto selo (Fragmento). In: Contos reunidos. Org. Boris Schnaiderman. São Paulo: Companhia das Letras, 2001, p. 261-269. Os trechos citados serão referenciados entre parênteses após as citações.
} 
1969, cinco anos após o golpe civil-militar que tomou o poder no Brasil e um ano depois do endurecimento da repressão política por meio do Al-5. Embora não apareça como a narrativa que intitula a coletânea de contos na qual se encontra inserida, ela possui uma importância capital no conjunto das narrativas ali reunidas. Como lembra José V. Mangueira, a epígrafe do livro Lúcia McCartney, uma passagem do "Apocalipse" referente aos males desencadeados com a abertura do quarto dentre os sete selos encontrados no "Livro das revelações", está diretamente relacionada ao texto literário aqui analisado. ${ }^{2} \mathrm{~A}$ leitura do respectivo fragmento inaugural, transcrito a seguir, evidencia esta afirmação:

E quando se abriu o quarto selo, ouvi a voz do quarto animal, que dizia: "Vem e vê". E apareceu um cavalo amarelo: e o que estava montado sobre ele tinha por nome Morte, e seguia-o o Inferno, e foi-lhe dado poder sobre as quatro partes da Terra, para matar à espada, à fome e pela mortandade, e pelas alimárias da Terra.

(Livro do Apocalipse - palavra grega que significa revelação.) $^{3}$

Tal destaque conferido a "O quarto selo (Fragmento)" pelo autor implícito ${ }^{4}$ naquela coletânea de contos pode ser explicado de duas formas. A primeira delas está relacionada ao desenvolvimento, ao longo do livro Lúcia McCartney, de uma temática já encontrada em narrativas do mesmo gênero das coletâneas Os prisioneiros (1963) e A coleira do cão (1965). Ela será desenvolvida nas obras seguintes de Rubem Fonseca, a exemplo de "Passeio noturno (Parte I)", "Passeio noturno (Parte II)", "Livro de ocorrências" e "O cobrador". 5 Nestes casos, encontramos a representação de realidades que, em razão de se mostrarem marcadas pela desagregação social, pela insatisfação e pelo desencanto dos personagens, são "apocalípticas". Entretanto, elas não indicam, como na narrativa bíblica, o advento de nenhum acontecimento "redentor", cuja materialização representaria um fim definitivo do sofrimento experimentado por aqueles indivíduos. O conto "Onze de maio", reunido no volume O cobrador (1979), desenvolve o tema apocalíptico de modo mais

\footnotetext{
2 Cf. MANGUEIRA, José Vilian. Cenas urbanas: a tematização da violência em cinco contos de Rubem Fonseca. Dissertação de Mestrado, Universidade Federal da Paraíba, João Pessoa, 2003, p. 35-36.

3 FONSECA, Rubem. Contos reunidos, op. cit., p. 235.

4 Para uma maior discussão sobre o conceito de autor implícito, recomendamos a leitura das obras: LEITE, Ligia Chiapinni Moraes. O foco narrativo. 4. ed. São Paulo: Ática, 1989 e BOOTH, Wayne. A retórica da ficção. Trad. Maria Teresa Guerreiro. Lisboa: Arcádia, 1980.

5 Cf. FONSECA, Rubem. Contos reunidos, op. cit., p. 396-397, p.398-402, p. 473-476 e p. 491-504.
} 
nitidamente semelhante a "O quarto selo". O contexto ali representado ocorre em um opressivo asilo para idosos de determinada sociedade do futuro, o qual parece ser relativamente próximo.

Neste sentido, estas narrativas seriam bastante ilustrativas daquilo que Frank Kermode denomina "Apocalipse moderno". ${ }^{6}$ Ele é caracterizado pelo desgaste emocional cada vez mais crescente entre os sujeitos modernos, provocado pelas recorrentes promessas frustradas de "fim dos tempos" ao longo dos séculos. Assim, tamanho seria o esfacelamento psicológico disto decorrente que os beneficiários da eventual materialização de uma "redenção" estariam impossibilitados de usufruir as benesses de tal "paraíso".

A outra forma de explicarmos o destaque conferido a "O quarto selo" dentre as narrativas de Lúcia McCartney está relacionada a determinado aspecto encontrado na composição daquele conto: a problematização ao princípio da causalidade como procedimento de estruturação da narrativa. Este seria desenvolvido nos contos "Passeio noturno (Parte I)", "Passeio noturno (Parte II)", "Livro de ocorrências" e "O cobrador" (os dois primeiros publicados no livro Feliz ano novo, de 1975, e os últimos sendo encontrados em O cobrador, $1979^{7}$ ).

Deste modo, se esta ruptura surge discretamente em "O quarto selo", estando relacionada apenas à possibilidade de determinadas informações presentes no texto terem o significado apresentado a seu respeito relativizado, já aparece mais abrangente no caso das narrativas "Passeio noturno (Parte I)" e "Passeio noturno (Parte II)". Nestes contos, ela envolve a relação de não causalidade - e, consequentemente, de não continuidade - entre duas tramas formalmente distintas. Em "Livro de ocorrências" e "O cobrador", por sua vez, a inexistência de um nexo causal ocorre entre cenas diferentes de uma mesma trama; neste último caso, tal característica é encontrada até, aproximadamente, a primeira metade da trama.

Como comentamos inicialmente, "O quarto selo" apresenta uma nítida intertextualidade com o "Apocalipse", indicada, inclusive, pela epígrafe do livro no qual foi publicado (embora não apareça indicada ali a referência à pas-

\footnotetext{
6 Cf. KERMODE, Frank. A sensibilidade apocalíptica. Trad. Melo Furtado. Lisboa: Século XXI, 1997.

7 Em nossa dissertação de mestrado (Aproveitamentos de rupturas estéticas de vanguarda em contos de Rubem Fonseca. Universidade Federal da Paraíba, João Pessoa, 2012) desenvolvemos um estudo comparativo entre o conto aqui analisado e as narrativas mencionadas. Nesta tipologia, analisamos as configurações de não causalidade na composição das respectivas tramas. Logo, verificamos também quais as possíveis funcionalidades desempenhadas por tais procedimentos nestes casos.
} 
sagem específica transcrita daquele texto bíblico). Esta narrativa bíblica diz respeito ao relato de acontecimentos futuros que se abaterão sobre a Terra, representando o "fim dos tempos" e o triunfo da esperança ansiada pelos cristãos. Neste contexto, ocorrerá a luta final entre o Bem e o Mal, com a consequente derrocada deste, bem como a conquista do paraíso celeste pelos homens justos, piedosos e tementes a Deus. Já a condenação ao inferno fica reservada para o restante da humanidade.

A abertura do quarto selo ou "selo do terror" aparece descrita no capítulo 6 , versículo 7 daquela narrativa bíblica. Após o Cordeiro abri-lo no livro de sete selos em forma de rolo e escrito de ambos os lados, entregue pela mão direita de quem se encontra assentado no trono, o quarto dentre os quatro seres viventes encarregados de acompanhar aquele convoca o cavaleiro Morte. Este surge montado em um cavalo amarelo e acompanhado de perto por Hades. Aos dois é concedido o poder de recorrer à espada, à fome, às pragas e aos animais selvagens para promover a morte sobre um quarto da superfície terrestre.

Logo na cena inaugural somos apresentados ao protagonista do conto, denominado Exterminador. No mesmo contexto, tomamos conhecimento da missão que lhe é encarregada pelo Cacique, líder da misteriosa organização terrorista a qual pertence o herói desta narrativa: assassinar o Governador Geral, a autoridade máxima daquela sociedade carioca do futuro mergulhada em toda sorte de demonstrações recorrentemente brutais de violência.

Assim, a relação desta trama com o "Apocalipse" também pode ser observada a partir da alcunha conferida àquele assassino profissional. A propósito, conforme lembra Mangueira ${ }^{8}$, o termo "exterminador", sendo um substantivo derivado do verbo "exterminar", pode significar, dentre outros significados possíveis, "destruição pela morte", "aniquilação" ou "ato de acabar com algo". Deste modo, podemos perceber que o Exterminador desempenha uma função análoga àquela do cavaleiro cuja aparição ocorre após a abertura do quarto selo na narrativa bíblica: atuar como um agente da morte. Todavia, no contexto recortado em "O quarto selo", a ação letal do herói é orientada pela meta de conseguir a eliminação do Governador Geral.

Desta forma, o Exterminador atua, simbolicamente, como o "cavaleiro Morte" que, auxiliado pelo "Inferno" (o personagem Cacique), “abrirá" o

8 MANGUEIRA, José Vilian. Cenas urbanas, op. cit., p. 115. 
"quarto selo" ou "selo do terror" naquela sociedade carioca do futuro já imersa em uma realidade apocalíptica. A narrativa começa claramente in medias res, pois supomos a abertura simbólica dos três selos anteriores àquele anunciado no título do conto. Neste sentido, o estado de beligerância de todos contra todos, descrito na trama, teria surgido em algum momento no qual um segundo selo ${ }^{9}$ houvesse sido aberto naquele contexto apocalíptico representado. A existência da narração deste episódio, de autoria do próprio Rubem Fonseca ou decorrente de algum exercício literário de outro escritor, continua por nós desconhecida.

Para entendermos melhor como o princípio da (não)causalidade aparece configurado em "O quarto selo", bem como as diferenças entre o caráter apocalíptico construído neste conto e aquele encontrado na narrativa bíblica, apresentaremos algumas explicações que julgamos necessárias sobre o contexto social representado no respectivo texto literário. Diversas informações presentes ao longo da trama apontam para a natureza apocalíptica do enredo desenvolvido na trama aqui analisada. A primeira delas surge logo na primeira cena, relacionada ao aprendizado de uma técnica de condicionamento (a capacidade de conter o ato reflexo de piscar os olhos frente a uma ameaça) pelo personagem Cacique. A propósito disto, ele comenta acerca da circunstância de ninguém mais ler naquela sociedade, metonímia cuja presença atuaria no sentido de indicar, embora ainda discretamente, a barbárie instalada nesta realidade. Isto seria indicado pelo abandono de qualquer preocupação em, pelo menos, ostentar uma conduta civilizada aparente, decorrente da educação formal proporcionada pelo contato com textos escritos.

“'Aprendi isso numa antiga novela americana sobre terroristas negros', disse o Cacique. 'É um truque velho, mas surpreendente. Hoje ninguém mais lê. Porém, tudo que eu sei aprendi nos livros.' Um leve sorriso na sua boca de lábios finos." (p. 261) Podemos perceber que a realidade representada em "O quarto selo" acontece no futuro a partir da presença de recursos tecnológicos inexistentes na época de publicação do conto. Por outro lado, baseando-nos

\footnotetext{
9 O relato sobre a abertura do segundo selo é encontrado no capítulo 6, versículo 3 do "Apocalipse". Nesta passagem, após o Cordeiro abri-lo no livro de sete selos (em forma de rolo e escrito de ambos os lados, entregue pela mão direita de quem se encontra assentado no trono), o segundo dentre os quatro seres viventes convoca o segundo cavaleiro. Este surge montado em um cavalo vermelho e recebe poder para acabar com a paz na Terra, incentivando, assim, os homens a matarem uns aos outros. Depois de anunciada sua missão, aquele cavaleiro recebe uma grande espada, simbolicamente destinada a este fim.
} 
parcialmente em Mangueira ${ }^{10}$, percebemos que esta narrativa aproveita quatro importantes aspectos relacionados ao momento histórico no qual a coletânea de contos Lúcia McCartney foi lançada para a construção de sua diegese.

O primeiro deles é a previsão do criminoso serial Charles Manson, relativa a uma guerra racial prestes a eclodir nos EUA. O anúncio dela, segundo a lógica paranoica deste indivíduo, estaria presente na música "Helter Skelter", dos Beatles, encontrada no aclamado Álbum Branco da banda, de 1968. Esta informação nos parece ter inspirado a concepção do comentário do personagem Cacique sobre suas leituras de "novelas americanas de terroristas negros".

Os outros três fatores são os seguintes: a existência de organismos de repressão do governo e de diversas organizações clandestinas de esquerda conhecidos pelas siglas que os identificavam; a exacerbação das práticas autoritárias da ditadura militar decorrente da publicação do Al-5 em 1968, representada na cena de tortura do chefe do grupo terrorista BBB nas dependências do órgão da polícia política; a chegada, pela primeira vez, de uma expedição tripulada por seres humanos à Lua em 1969, mesmo ano de lançamento daquele livro de contos. Este fator externo aparece reelaborado esteticamente quando o narrador heterodiegético ${ }^{11}$ (terceira pessoa) destaca a sofisticação técnica do treinamento recebido pelo Exterminador ao comparar esta preparação com aquela recebida pelos "antigos astronautas". Assim demonstra o trecho, abaixo transcrito, do final da primeira cena deste texto literário:

$\mathrm{R}$ controlava os mínimos gestos - comer, andar, sentar, correr, fumar, até a maneira de pensar ele condicionava ao personagem assumido. $O$ treinamento dos Exterminadores para enganar e matar era tão elaborado e difícil quanto o dos antigos astronautas. (p. 262)

Embora haja desenvolvimento tecnológico nesta sociedade do futuro, a ponto de ser possível a comunicação, em tempo real, entre duas pessoas mediante um sofisticado sistema de audiovisual instalado na parede de uma sala,

\footnotetext{
${ }_{11}^{10}$ MANGUEIRA, José Vilian. Cenas urbanas, op. cit., p. 119.

${ }^{11}$ Mais adiante comentaremos, em outra nota, sobre a hipótese de Mangueira que pode ajudar a entender a razão de o narrador de "O quarto selo" ser heterodiegético, e não autodiegético como os narradores dos demais contos reunidos para constituir o corpus de nossa pesquisa de mestrado.
} 
como podemos observar nos diálogos ocorridos entre Pan e o Governador Geral; ou na sessão de tortura do chefe do grupo terrorista BBB realizada pelo primeiro, quando o monitor chega a sair do nicho da parede onde está encaixado para ficar próximo ao torturado por alguns instantes, não encontramos indícios da existência do menor sentimento de empatia nos indivíduos que convivem naquele espaço. Logo no início da segunda cena do conto, a advertência exposta na portaria do hotel já indica o estado de insegurança e desconfiança reinantes naquela cidade: "Na portaria do hotel, em grandes letras de vapor de mercúrio, estava escrito: SE VOCÊ NÃO CONHECE HÁ MUITO TEMPO ESSE(A) HOMEM (MULHER) QUE ESTÁ COM VOCÊ, NÃO VÁ PARA A CAMA COM ELE(A). PROTEJA SUA VIDA." (p. 262)

Além de a relação entre os indivíduos nesta sociedade ser caracterizada pela insegurança e desconfiança mútuas, encontramos indícios relativos à incapacidade de eles se relacionarem de forma minimamente emocional com alguém (mesmo no caso de um encontro destinado simplesmente para o sexo casual). A representação metonimicamente simbólica disto pode ser observada na descrição do ato sexual realizado entre o Exterminador e uma mulher de identidade desconhecida no quarto do mesmo hotel mencionado anteriormente. O modo esquemático como o narrador descreve tal situação tem por finalidade enfatizar a falta de empatia mútua entre estes personagens. Deste modo, eles precisam recorrer a práticas sexuais sadomasoquistas com o objetivo de buscar alcançar algum tipo de sensação delas decorrente, mesmo que isto não represente, no final das contas, uma mudança significativa na qualidade do conjunto da experiência ocorrida naquele espaço. ${ }^{12}$

O Exterminador e a mulher foram para o quarto.

O Exterminador trancou a porta.

O Exterminador e a mulher tiraram a roupa.

A mulher deitou-se na cama.

O Exterminador abriu a bolsa da mulher e retirou um IAAP de couro de alumínio. (IAAP: Instrumento de Algolagnia Ativo-Passiva.)

\footnotetext{
${ }^{12}$ No conto "O campeonato", encontrado no livro Feliz ano novo, publicado em 1975, percebemos um aproveitamento desta característica encontrada na sociedade do futuro representada em "O quarto selo". Naquela narrativa, deparamo-nos com a representação de um contexto social marcado pela ausência de afetos entre os indivíduos. Assim, as atividades de "conjunção carnal" estão reservadas a campeonatos realizados secretamente após terem sido reduzidos à condição de clandestinidade. Nestes torneios, uma comissão de especialistas escolhe o vencedor depois de avaliar, minuciosamente, 0 desempenho de cada candidato. Tais performances também contam com a presença de um público espectador, composto, em sua maioria, de pessoas do sexo feminino, conforme comenta o narrador autodiegético (primeira pessoa) a certa altura da trama.
} 
Da cama, excitadamente, a mulher perguntou: "Você não é um SS, é?". O corpo dela estava todo arrepiado. (SS: Super Sádico, pessoas que somente sentem prazer matando o parceiro ou parceiros no ato sexual.)

[...]

A mulher cobriu os seios com as mãos.

O Exterminador golpeou a barriga da mulher.

Finos riscos de sangue brotaram na pele da mulher.

A mulher virou de costas. Suas nádegas estavam contraídas. Gemidos abafados saíam da sua boca. O Exterminador golpeou as costas e as nádegas da mulher.

O Exterminador deitou-se ao lado da mulher, sobre as marcas de sangue que o seu corpo deixara no lençol. O Exterminador abraçou a mulher com força, mordendo-a na boca até sentir o sangue doce molhar sua língua.

'Amor, me ama, amor', disse a mulher, pronunciando passionalmente A Grande Palavra do CO.

'Amor, amor', disse o Exterminador. (CO: Código de Obscenidades, coleção de palavras de uso rigorosamente interdito.) (p. 263-264)

Por outro lado, é importante lembrarmos que a própria distribuição dos espaços neste Rio de Janeiro do futuro atua como base material destinada a fomentar a insensibilidade, a desconfiança e a insegurança entre os habitantes da cidade. Mesmo Ipanema e Copacabana, bairros notoriamente conhecidos por possuir habitantes com maior poder aquisitivo, tornaram-se apenas mais duas favelas em uma sociedade onde somente esta modalidade precarizada de habitação parece existir. São nestes lugares que vinte milhões de pessoas simplesmente convivem amontoadas.

Neste contexto, as insurreições da população são frequentes e as taxas de mortalidade delas decorrentes mostram-se bastante elevadas, a ponto de os sociólogos considerarem oito mil mortes em uma semana um "pequeno número de perdas". A massificação destes óbitos, e a banalização da vida disto decorrente, tornam insensíveis também os garis encarregados do recolhimento dos corpos de civis espalhados nas ruas, cujo destino é a incineração, sem haver sequer a retirada de suas roupas, em fornos subterrâneos localizados na Praça XV e no Largo da Carioca. O nível de insensibilidade e automatismo dos profissionais responsáveis por este tipo de "limpeza" é notório: ao verem um colega de trabalho fulminado em serviço, após ter sido alvejado por um atirador localizado na janela de um prédio, eles simplesmente olham para o corpo caído e o recolhem prontamente à cremação, sem demonstrar qualquer tipo de emoção ou empatia neste caso.

Em meio a esta realidade apocalíptica instaurada, surge o Exterminador, designado por uma organização secreta de natureza desconhecida para matar 
o mais proeminente representante de um poder que demonstra estar apenas preocupado em preservar - e, quiçá, aumentar - a situação de permanente estado de guerra existente naquela sociedade. Ao longo do conto, aquele personagem somente aparece sob a identidade de Exterminador nas duas primeiras cenas do conto. No final da narrativa, descobrimos que ele estivera atuando ali o tempo inteiro, mas disfarçado de Pan Cavalcanti, com o objetivo de ter acesso mais facilitado ao Governador Geral, disfarçando-se de um homem da confiança deste.

Como podemos observar, o Exterminador possui uma meta bastante nítida a alcançar no contexto social representado em "O quarto selo". Esta característica do conto nos parece importante para ajudar a entender um aspecto que a composição desta narrativa apresenta, estruturada a partir do princípio da não causalidade. Assim, as cenas encontradas nesta trama são dispostas segundo um nexo de causalidade, embora haja uma alternância de focalização da narração entre os acontecimentos ocorridos em diferentes contextos da diegese. Isto decorre da relação dialética entre forma e conteúdo ali configurada, pois a presença de um herói com uma missão, mesmo que não seja ela relacionada a uma iniciativa individual ${ }^{13}$, acaba atuando como um motivo cujos efeitos podem ser percebidos na construção deste texto literário.

Por outro lado, "O quarto selo" apresenta uma série de explicações relativas a algumas siglas. Nestes casos, a verossimilhança se mostra, recorrentemente, passível de questionamento, mesmo quando não parece haver maiores razões para problematização em alguns casos. Arturo Gouveia argumenta que a presença destes códigos patéticos no conto representa uma paródia, até então inédita na literatura brasileira pós-64, a recursos adotados pela repressão ideológica durante a ditadura militar brasileira. ${ }^{14}$

Exemplo destes recursos são as intervenções dos censores nas produções

${ }^{13}$ Em sua pesquisa de mestrado, Mangueira destaca a diferença existente entre as motivações das ações dos heróis marginais nas narrativas "Feliz ano novo", "O cobrador" e "O quarto selo". Neste sentido, os protagonistas dos dois primeiros exemplos, cada qual ao seu modo, agem movidos por iniciativas individuais decorrentes das privações sociais por eles sofridas na sociedade onde vivem. No caso da última narrativa, o herói marginal age em nome de uma misteriosa organização terrorista. As atitudes condicionadas demonstradas pelo protagonista, resultantes de seu rigoroso treinamento, ilustrariam a ausência de uma vontade própria que motive suas ações. Além disto, para o autor do referido trabalho, este conto também demonstraria a inexistência de uma motivação pessoal nas condutas do Exterminador. Isto estaria relacionado com a circunstância de esta produção literária ser a única, dentre os textos literários mencionados, a apresentar um narrador heterodiegético em sua composição. Neste sentido, ele atuaria como um "olhar externo", uma espécie de "câmera" a conduzir a construção deste enredo.

${ }^{14}$ Cf. GOUVEIA, Arturo. A ordem e o progresso da agonia. In: A semente do capataz: ensaios sobre a ficção brasileira pós-64. João Pessoa: s/d. (inédito) 
artísticas e intelectuais do período, quando eles vetavam determinados trechos considerados "subversivos" e/ou incluíam comentários nestes excertos vetados, segundo critérios estritamente arbitrários. Ainda segundo Gouveia, um procedimento composicional semelhante ao adotado na trama de "O quarto selo" seria encontrado posteriormente no romance Zero, de Inácio de Loyola Brandão, publicado no Brasil em 1975.

As siglas que surgem em certos momentos evidenciariam uma relação de causalidade relativa frente ao conjunto da composição do conto. Isto pode ser assim explicado: por um lado, aquelas informações encontradas na narrativa podem ser trocadas por outras de natureza também duvidosa, sem prejuízo do entendimento da trama; por outro, percebemos a existência de uma vinculação simbólica entre este procedimento narrativo e o conjunto da diegese. Neste caso, a eliminação do recurso narrativo propriamente dito acabaria comprometendo a apreensão da totalidade da obra literária, pois sua presença desempenha uma funcionalidade importante no sentido de se articular com determinados aspectos presentes no texto.

Deste modo, tal recurso narrativo está relacionado à duvidosa explicação de siglas encontradas em uma sociedade cujo poder demonstra somente estar preocupado em intervir, de forma tirânica, na vida das pessoas. Neste contexto, as insatisfações delas, decorrentes da ausência das mais elementares condições de existência humana, são brutalmente reprimidas. Por sua vez, outro efeito de sentido decorrente daquele procedimento estético pode ser entendido como complementar ao primeiro, inexistindo qualquer problema de solução de compatibilidade entre um e outro. Ao contrário, esta convergência de sentidos complementares contribui para o enriquecimento da construção da trama e, consequentemente, para a ampliação das possibilidades de sua fruição estética pelos leitores.

Assim, a intervenção destas explicações, apenas aparentemente adequadas às siglas mencionadas ao longo da narrativa, estaria também relacionada simbolicamente ao jogo de disfarce adotado pelo Exterminador. Como comentamos anteriormente, após aparecer nas duas primeiras cenas da trama, ele somente ressurge na última cena do conto, quando, finalmente, descobrimos que estivera disfarçado de Pan Cavalcanti, homem de confiança do Governador Geral. Esta peripécia se evidencia no momento em que aquele personagem saca sua arma e dispara um tiro certeiro em direção ao olho direito do "GG", matando-o instantaneamente. Logo, aquele recurso narrativo pode ser 
entendido como um conjunto de prolepses ou antecipações que, progressivamente, apontam para a revelação final de "O quarto selo", oportunidade na qual se torna possível vislumbrarmos este efeito de sentido até então encoberto.

"O quarto selo" não é um conto no qual o caráter apocalíptico surge implicitamente, insuspeito em uma trama cujas características parecem estar relacionadas apenas a questões inspiradas na materialidade dos acontecimentos sociais. Deste modo, além de o título do conto indicar o cunho mítico inspirado no "Apocalipse" bíblico, outros aspectos ali encontrados desempenham função semelhante. Exemplos disto são a natureza futura dos eventos narrados, a impossibilidade de determinarmos em que momento eles se tornarão realidade e a descrição de um contexto social assolado por grandes males e sofrimentos. Contudo, após indicarmos as semelhanças existentes entre esta narrativa e a bíblica, devemos destacar as diferenças entre ambas, para privilegiarmos o mais importante em nossa análise: a singularidade do texto literário analisado.

O próprio subtítulo "(Fragmento)" indica que esta narrativa é apenas uma parte não somente de uma trama desconhecida e supostamente mais abrangente, mas também do conjunto do contexto social representado naquele conto. Em outras palavras, podemos afirmar que este texto literário trata somente da parcela de determinado episódio maior e ignorado na sua totalidade, o qual, por sua vez, já seria recortado de um relato ainda mais amplo que se poderia considerar completo como o "Apocalipse" bíblico. Assim, uma vez percebido este aspecto, devemos buscar entender o efeito de sentido dele resultante por meio da reflexão acerca da relação entre forma e conteúdo configurada neste caso. A propósito, devemos considerar também outro componente estrutural, constituído ao final desta obra literária: a possibilidade de acréscimo indefinido de novos episódios.

Como destacamos anteriormente, o Exterminador possui uma meta definida a ser alcançada, o que nos parece permitir a configuração de uma relação de causalidade entre as cenas dispostas na trama. Entretanto, não encontramos, ao longo da narrativa, nenhum indício sobre as características da organização a qual pertence aquele personagem; nem, muito menos e principalmente, a descrição de qualquer projeto político destinado à busca de uma mudança estrutural da realidade encontrada na cidade representada no conto. Este último aspecto não nos parece gratuito, estando relacionado a uma ques- 
tão histórica de nosso país: o caráter estruturalmente autoritário de nossa sociedade.

Neste sentido, há uma passagem bastante reveladora no final da oitava cena, cuja presença nos parece evidenciar e mesmo explicar, discretamente, a natureza problemática configurada ao longo do conto e tornada ainda mais evidente no seu desfecho aparente. A cena em questão se passa nos subterrâneos da DEPOSE, o órgão responsável pela prisão e tortura de quem for considerado subversivo pelo governo de exceção da sociedade representada na narrativa. Após o velho guarda relatar para seu aprendiz como funcionam as diferentes técnicas de tortura, ele aconselha o rapaz a agarrar a chance daquele emprego "com unhas e dentes", pois este seria um cargo garantido "para o resto da vida". Segundo o veterano torturador, não há possibilidade de ocorrer uma mudança na "índole" do povo brasileiro.

O significado do termo "índole" neste trecho é indeterminado e, em nenhum momento posterior da narrativa, aparece qualquer explicação destinada a desfazer esta indeterminação. Entretanto, ao articularmos a referida passagem do conto com seu final, pensamos que este conselho no término da oitava cena remete diretamente à seguinte problematização construída ao longo da narrativa e reforçada no desfecho da trama: mudam-se as pessoas no poder, mas isto não representa nenhum tipo de mudança significativa no estado de coisas vigente. Logo, independentemente de quem assuma tal posição, a sociedade permanece, estrutural e psicologicamente, autoritária, excludente, brutal, sem se vislumbrar alguma esperança de alteração substancial desta estrutura social. ${ }^{15}$

Pan Cavalcanti, identidade incorporada fisicamente pelo Exterminador por meio das avançadas técnicas da medicina existentes naquela sociedade do futuro, é uma nomeação que possui significados reveladores. Eles nos parecem estar relacionados simbolicamente com o caráter labiríntico configurado na narrativa. Aquele prenome, em sua forma escrita, significa "todo, totalidade", enquanto sob a modalidade pronunciada (Pã) se relaciona ao deus

\footnotetext{
${ }^{15}$ Sem extrapolarmos o enfoque deste trabalho, a análise do texto literário, percebemos que, irônica, mas não surpreendentemente, a intuição do velho guarda do órgão estatal repressivo em "O quarto selo" vem se confirmando historicamente na realidade brasileira. O Brasil, após o período autoritário vivido entre 1964-1985, é o único país latino-americano a não punir nenhum dos agentes estatais responsáveis por perseguir, torturar e matar aqueles considerados opositores políticos ao regime ditatorial de então. Esta impunidade tem gerado graves efeitos na contemporaneidade brasileira, a exemplo do aumento das práticas de tortura nos presídios nacionais e da violência policial contra negros, pobres e moradores das favelas. Vide TELES, Edson; SAFATLE, Vladimir (Orgs.). O que resta da ditadura: a exceção brasileira. São Paulo: Boitempo, 2010.
} 
grego da dissonância e desarmonia, de onde surgiu a palavra "pânico". No tocante a este significado, assim explica Affonso Romano de Sant'Anna, a propósito da análise do poema "Cachoeira de Paulo Afonso", de Castro Alves:

Como no mito, Pan (sic) vive à espreita das ninfas em bosques, florestas e fontes. E é nesse cenário que, ao se banhar, Maria se vê possuída de "pânico", quando surge imprevistamente um personagem que a persegue como um sátiro. Como se sabe, o deus Pan (sic) emprestou "seu nome à palavra pânico, este terror que se expande na natureza e no ser, sentimento da presença desse deus que tumultua o espírito e enlouquece os sentidos". Mas Pan (sic) é sobretudo o deus violador. Violação com a violência que isso implica. ${ }^{16}$

O significado deste primeiro nome ("toda dissonância") surge relacionado com a semântica de um sobrenome cuja etimologia remete a uma das famílias mais tradicionais de Portugal, instalada no Brasil desde a época das capitanias hereditárias. Assim, a incorporação da identidade associada a estes nomes pelo protagonista indica, simbolicamente, que aquele herói manterá, quiçá reforçará, contradições estruturais cujas raízes remontam ao período colonial brasileiro e persistem em uma sociedade do futuro. Neste contexto, mesmo os avanços tecnológicos não conseguem mascarar estes arcaicos impasses.

Tais impasses também podem ser percebidos a partir do nome atribuído à autoridade máxima daquela sociedade (o Governador Geral). A denominação deste cargo remete aos mandatários encarregados de administrar as grandes extensões de terra doadas pela Coroa Portuguesa no Brasil colonial. Esta medida originou os latifúndios, responsáveis pela secular concentração de terra neste país. Por outro lado, a quantidade de cenas existentes em "O quarto selo" (onze no total) é outra indicação, do ponto de vista simbólico, da natureza labiríntica configurada na trama. Este número, sendo um palíndromo, sugere a ideia de algo que mantém o mesmo sentido independentemente da direção adotada (no caso em questão, da direita para a esquerda, ou da esquerda para a direita).

Desta forma, podemos afirmar que "O quarto selo" representa um mito apocalíptico negativo, cuja negatividade repercute na própria fatura - e fratura - da construção mítica. Esta, por sua vez, representa a própria falência relacionada à esperança do advento de qualquer redenção futura para o con-

\footnotetext{
${ }^{16}$ SANT'ANNA, Affonso Romano de. Canibalismo amoroso: o desejo e a interdição em nossa cultura através da poesia. 4. ed. Rio de Janeiro: Rocco, 1985.
} 
texto da sociedade carioca representada no conto (e, extensivamente, do conjunto da sociedade brasileira). O caráter fragmentado desta trama estiliza a impotência mesmo de se conseguir sequer narrar uma história completa, o que estaria relacionado ao desgaste vivido por quem espera o "triunfo da esperança" nunca realizado. ${ }^{17}$

Além disto, a natureza inconclusa da narrativa, reforçada no seu final, aponta para a possibilidade de novos episódios serem acrescentados indefinidamente, demonstrando, assim, a repetição labiríntica, ad infinitum, do contexto social representado na diegese. ${ }^{18}$ Neste sentido, como argumenta Frank Kermode, caso estes indivíduos pudessem, eventualmente, conquistar algum "paraíso", estariam tão devastados psiquicamente que não conseguiriam usufruir qualquer benesse decorrente desta nova realidade. ${ }^{19}$

Por outro lado, devemos entender este aspecto apocalíptico e negativo de "O quarto selo" segundo as especificidades de nossa formação cultural, a qual, segundo José Antonio Pasta Jr., caracteriza-se por seu caráter supressivo. ${ }^{20}$ Deste modo, como argumenta o mesmo autor, na Europa, as aparências dos valores liberais de igualdade, liberdade e fraternidade para todos somente começaram a ruir com a "Primavera dos Povos" de 1848. Naquele continente, elas se tornaram definitivamente insustentáveis após o surgimento de Auschwitz na Segunda Guerra Mundial. No Brasil, país que foi considerado da periferia do capitalismo durante séculos, as contradições já surgem escancaradas, a céu aberto, sem disfarces. Em outras palavras, a elaboração de um disfarce minimamente convincente para camuflar tal realidade mostra-se inviável.

Neste contexto, como analisa Roberto Schwarz, reinam desbragadamente

${ }^{17}$ Este aspecto formal configurado em "O quarto selo" está relacionado a um dos procedimentos percebidos por Adorno na composição das criações artísticas mais radicais do século XX: a categoria do estado do problema (Cf. ADORNO, Theodor. Teoria estética. Trad. Artur Morão. Lisboa: Edições 70, 1982). Segundo Arturo Gouveia, ela representa aquilo que as forças produtivas concebem em seu estágio mais avançado, pois revela a capacidade própria das obras de arte de não somente preservar, mas também potencializar posições críticas relativas à realidade e até mesmo à fatura da arte. Tais circunstâncias proporcionam rupturas com padrões ou modelos estéticos já consagrados. Cf. GOUVEIA, Arturo. Palavras mutiladas: Borges e Osman Lins à luz de Adorno. In: Escritos adornianos. João Pessoa: Ideia, 2010, p. 123-138.

${ }^{18}$ Em sua dissertação, Mangueira comenta sobre a possibilidade de a violência existente na sociedade do futuro, representada em "O quarto selo" continuar após o assassinato do Governador pelo Exterminador. Entretanto, aquele autor não desenvolve esta intuição em seu trabalho, buscando compreender, como estamos nos propondo a analisar aqui, a reconfiguração do externo na construção estética e a relação entre forma e conteúdo estabelecida nesta obra literária.

19 Cf. KERMODE, Frank. A sensibilidade apocalíptica, op. cit.

${ }^{20}$ Cf. PASTA JR., José Antonio. O romance de Rosa: temas do Grande Sertão e do Brasil. Novos Estudos CEBRAP, São Paulo, n. 55, p. 61-70, 1999, e Volubilidade e ideia fixa: o outro no romance brasileiro. Revista Sinal de Menos, v. 2, n. 4, p. 13-25, 2010. 
a desfaçatez e a ausência de qualquer projeto destinado à coletividade dotado de alguma continuidade. ${ }^{21}$ Assim, pondera Pasta Jr., a literatura brasileira se forma negativamente a partir de Machado de Assis, em meio a uma sociedade que não se formou (ou, argumentaríamos dialeticamente, teria esta se formado também de modo negativo). ${ }^{22}$ Logo, o autor discorda de Antonio Candido, para quem a literatura nacional teria se formado com esse escritor carioca sem revelar negatividade em relação a uma realidade social não formada. $^{23}$

O legado das obras machadianas, prossegue Pasta Jr., consolidou uma tradição constituída pela "ruína", pela "nulidade", pelo "romance impossível", pelo "ponto de vista da morte", orientada pela "própria supressão e impossibilidade". ${ }^{24}$ A ressonância disto pode ser encontrada em obras de escritores brasileiros posteriores a Machado, como Mário de Andrade, João Guimarães Rosa e Clarice Lispector, podendo Rubem Fonseca também figurar neste grupo, conforme podemos perceber em nossa análise de "O quarto selo".

\section{O TERROR QUE PERMANECE}

A ditadura civil-militar brasileira terminou em 1985. Contudo, os fantasmas autoritários daquele período continuam presentes no Brasil. A Lei da Anistia, de 1979 , concedeu perdão não somente àqueles perseguidos, acusados, condenados e/ou exilados por crimes políticos. Os perseguidores, torturadores, assassinos e estupradores daqueles considerados "subversivos" acabaram sendo indevidamente beneficiados pela mesma lei. O benefício a estes agentes de Estado, consequência de uma exigência política da época de publicação desta legislação, ainda hoje permanece em vigor, apesar de tantas críticas.

A impunidade em relação às arbitrariedades promovidas pelo poder estatal ou por ele apoiadas naquele momento histórico produz um legado. Este permite a continuidade e mesmo a potencialização de tais práticas autoritárias. Assim, o Brasil ainda possui uma polícia militarizada, com índices de letalidade bastante elevados (maiores do que aqueles encontrados nos países em situa-

${ }^{21}$ Cf. SCHWARZ, Roberto. As ideias fora do lugar. In: Ao vencedor as batatas. 3. ed. São Paulo: Duas Cidades, 1992, p. 13-28, e Sequências brasileiras: ensaios. São Paulo: Companhia das Letras, 1999.

${ }^{22}$ Cf. PASTA JR., José Antonio. Volubilidade e ideia fixa, op. cit., p. 11.

${ }^{23}$ Cf. CANDIDO, Antonio. Formação da literatura brasileira: momentos decisivos. Belo Horizonte/Rio de Janeiro: Itatiaia, 1975.

24 PASTA JR., José Antonio. Volubilidade e ideia fixa, op. cit., p. 11. 
ção de guerra) e que recorre à tortura como forma de atuação. Neste sentido, esta prática também pode ser largamente constatada nos presídios brasileiros, sendo promovida pelos agentes penitenciários.

Diante de circunstâncias como estas, percebemos que a previsão do velho agente de polícia política para seu pupilo em "O quarto selo" acabou se concretizando na sociedade brasileira. Deste modo, a memória histórica daquela época necessita ser recuperada e, portanto, reconstituída amplamente. Neste processo, os algozes de então devem ser punidos pelos crimes cometidos, permitindo às vítimas terem os prejuízos sofridos devidamente reparados. Do contrário, a história tornará a retornar sob a forma de ruína. 